\title{
Screening for serological biomarkers of pancreatic cancer by two-dimensional electrophoresis and liquid chromatography-tandem mass spectrometry
}

\author{
YUFENG WANG $^{1}$, YASUHIRO KURAMITSU ${ }^{1}$, SHIGEFUMI YOSHINO ${ }^{2}$, MOTONARI TAKASHIMA ${ }^{2}$, \\ XIULIAN ZHANG ${ }^{1}$, TOMIO UENO ${ }^{2}$, NOBUAKI SUZUKI ${ }^{2}$, MASAAKI OKA ${ }^{2}$ and KAZUYUKI NAKAMURA ${ }^{1}$ \\ Departments of ${ }^{1}$ Biochemistry and Functional Proteomics and ${ }^{2}$ Digestive Surgery of Applied \\ Molecular Bioscience, Yamaguchi University Graduate School of Medicine, Ube, Japan
}

Received January 25, 2011; Accepted March 17, 2011

DOI: $10.3892 /$ or.2011.1278

\begin{abstract}
Pancreatic cancer (PC) is one of the most lethal malignant tumors because of late diagnosis and the lack of response to various therapies. To identify potential biomarkers in cancerous serum from early stage PC patients, we carried out two-dimensional gel electrophoresis (2-DE) and liquid chromatography-tandem mass spectrometry (LC-MS/MS) to compare the serum proteomic profiles from 45 patients with PC and 20 healthy volunteers. Seven spots showed differential expression on 2-DE gels and two up-regulated protein spots were identified by LC-MS/MS as $\alpha-1$-antitrypsin (AAT). These protein spots were also confirmed by Western blotting. This is the first time that AAT isoforms have been identified as potential serum biomarkers for PC. The serum isoforms of AAT may be clinically useful for PC diagnosis and monitoring.
\end{abstract}

\section{Introduction}

Pancreatic cancer (PC) is one of the most lethal malignant tumors in human diseases. Median survival is $<12$ months and overall 5-year survival is $<5 \%$ after aggressive multimodality treatment. Because of rapid aggressiveness and low probability of diagnosis at an early stage, most cases are diagnosed after metastatic spread (1). Therefore, detection of $\mathrm{PC}$ at an early disease stage is critical for successful clinical therapy. Although the serum tumor marker CA19-9 has been widely used for PC, it lacks sufficiently sensitive and accurate, especially in early diagnosis (2). There is, therefore, an urgent

Correspondence to: Dr Yasuhiro Kuramitsu, Department of Biochemistry and Functional Proteomics, Yamaguchi University Graduate School of Medicine, 1-1-1 Minami-Kogushi, Ube, Yamaguchi 755-8505, Japan

E-mail: climates@yamaguchi-u.ac.jp

Key words: two-dimensional gel electrophoresis, liquid chromatography-tandem mass spectrometry, pancreatic cancer need to discover more sensitive and specific biomarkers to improve diagnosis and also prognostic monitor for patients of PC.

The combination of two-dimensional gel electrophoresis (2-DE) with mass spectrometry (MS) is a powerful tool for identification of novel biomarkers or therapeutic targets from cancer-associated samples (3). In previous proteome studies, this technique has been applied successfully to identify various proteins in cancer cell lines, cancer tissues and sera from cancer patients $(4,5)$ and has been used to detect biomarkers of colorectal cancer (6), ovarian cancer (7), breast cancer $(8)$, prostate cancer $(9,10)$, bladder cancer $(11)$ and other cancers. The detection for biomarkers is clinically useful, especially for screening or diagnosis.

In recent years, many efforts have been made to identify biomarkers by these proteomic methods. Bloomston et al identified fibrinogen $\gamma$ as a potential tumor marker for pancreatic cancer (12). Yu et al confirmed that apolipoprotein E, $\alpha$-1-antichymotrypsin and inter- $\alpha$-trypsin inhibitor increased in pancreatic cancer serum (13). Sun et al discovered that cyclin I and GDI2 may be potential molecular targets for pancreatic cancer diagnostics and therapeutics (14). Thus, we will continue applying them to validate the candidate tumor markers and also improve the current proteomic method.

In the present study, we utilized proteomic differential display analysis using 2-DE with LC-MS/MS to examine the difference in serum proteins between normal and PC patients. We discuss the usefulness of electrophoretic techniques to find serum tumor biomarker candidates which might be a promising target for diagnosis of PC in early stage.

\section{Materials and methods}

Serum specimens and sample preparation. A total of 65 serum samples were used, with 45 samples randomly selected from patients with pancreatic cancer, who had undergone surgical resection at the Department of Surgery II, Yamaguchi University Hospital and 20 samples obtained from healthy donors as controls. Written informed consent was obtained from all patients before surgery. All serum samples were stored at $-80^{\circ} \mathrm{C}$ until use. 
A

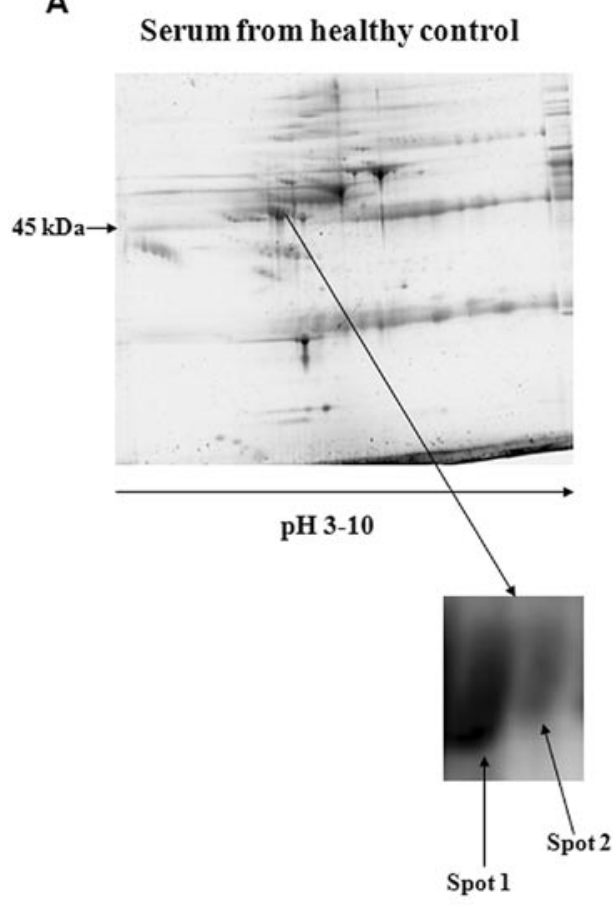

B

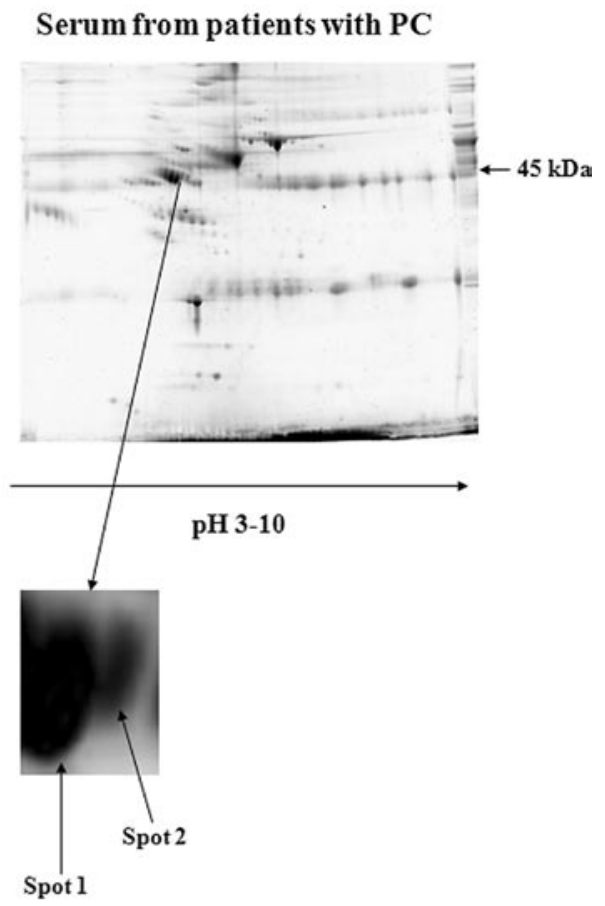

Figure 1. Protein patterns obtained by 2-DE of serum from patients with PC (A) and healthy controls (B). Proteins were separated on pH 3-10 linear, immobilized $\mathrm{pH}$ gradient strips and then by SDS-PAGE with a linear concentration gradient of 5-20\%. Gels were stained with Flamingo Gel Stain ${ }^{\mathrm{TM}}$. Two spots were up-regulated in cancerous serum and numbered 1 and 2.

Table I. Up-regulated $\alpha$-1-antitrypsin (AAT) isoforms in PC sera.

\begin{tabular}{lccccccc}
\hline Isoform $^{\mathrm{a}}$ & Protein name & Accession no. & $\mathrm{pI}^{\mathrm{c}}$ & $\begin{array}{c}\text { Molecular } \\
\text { weight }(\mathrm{Da})^{\mathrm{c}}\end{array}$ & $\begin{array}{c}\text { Distinct } \\
\text { peptides }^{\mathrm{d}}\end{array}$ & $\begin{array}{c}\text { MS/MS search } \\
\text { score }\end{array}$ & $\begin{array}{c}\text { Sequence } \\
\text { coverage }^{-}\end{array}$ \\
\hline 1 & $\alpha-1$-antitrypsin & P01009 & 5.37 & 46736.8 & 14 & 190.84 & $32 \%$ \\
2 & $\alpha-1$-antitrypsin & P01009 & 5.37 & 46736.8 & 5 & 56.20 & $10 \%$ \\
\hline
\end{tabular}

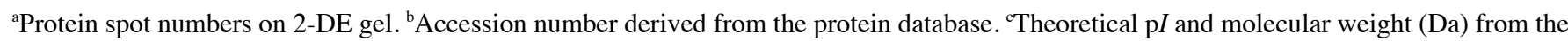
protein database. ${ }^{\mathrm{d}}$ Number of matched peptides.

Albumin and $\mathrm{IgG}$ were removed by using ProteoPrep ${ }^{\mathrm{TM}}$ Blue Albumin depletion kit (Sigma, St. Louis, MO, USA) from serum samples following product information of this kit. Separated samples were obtained and stored at $-80^{\circ} \mathrm{C}$ until analysis.

2-DE. Isoelectric focusing (IEF) was performed on $11 \mathrm{~cm}$, immobilized $\mathrm{pH}$ gradient strips with a linear gradient pH 3.0-10.0 (Bio-Rad, Hercules, CA, USA) at 50 A/strip. Protein $(100 \mu \mathrm{g})$ was used for each 2-DE. Samples were mixed with $200 \mu 1$ of rehydration buffer [ $8 \mathrm{M}$ urea, $2 \%$ CHAPS, $0.01 \%$ bromophenol blue, $1.2 \%$ Destreak reagent (GE Healthcare, Uppsala, Sweden)] and 0.5\% IPG buffer (GE Healthcare) and loaded into the IPGphor strip holder (GE Healthcare). IEF was performed in six steps which were: rehydration for $10 \mathrm{~h}$ (no voltage), 0 to $500 \mathrm{~V}$ for $4 \mathrm{~h}, 500$ to $1000 \mathrm{~V}$ for $1 \mathrm{~h}, 1000$ to $8000 \mathrm{~V}$ for $4 \mathrm{~h}, 8000 \mathrm{~V}$ for $20 \mathrm{~min}$, and the final phase of $500 \mathrm{~V}$ from 20000 to $30000 \mathrm{Vh}$. The IPG strips were equilibrated as described previously and then transferred onto the gels, run at $200 \mathrm{~V}$. SDS-PAGE was performed on a precast polyacrylamide gel with a linear concentration gradient of 5-20\% (Bio-Rad) (15).

Fluorescence staining. The SDS-PAGE gels were fixed with the $40 \%$ ethanol and $10 \%$ acetic acid for $2.5 \mathrm{~h}$ and then stained with a fluorescent gel staining, Flamingo ${ }^{\mathrm{TM}}$ Fluorescent Gel Stain (Bio-Rad) for $18 \mathrm{~h}$. The stained gels were washed with Milli-Q water 3 times for $5 \mathrm{~min}$. All experimental procedures were carried out on a shaker.

Image analysis and spot picking. The gels were scanned by using the ProXpress 2D Proteomic Imaging System (PerkinElmer, Waltham, MA, USA) in order to record the positions of the protein spots on the gel. Image analysis was performed with Progenesis Samespots software (Nonlinear, Newcastle, Upon Tyne, UK) following the user manual. After image analysis, the gels were stained with See Pico ${ }^{\mathrm{TM}}$ (Benebiosis Co, Ltd., Seoul, Korea) over night. The selected protein spots that showed at different intensities were excised from the gels and stored in $100 \mu \mathrm{l}$ Milli-Q water at $-80^{\circ} \mathrm{C}$ until analysis. 


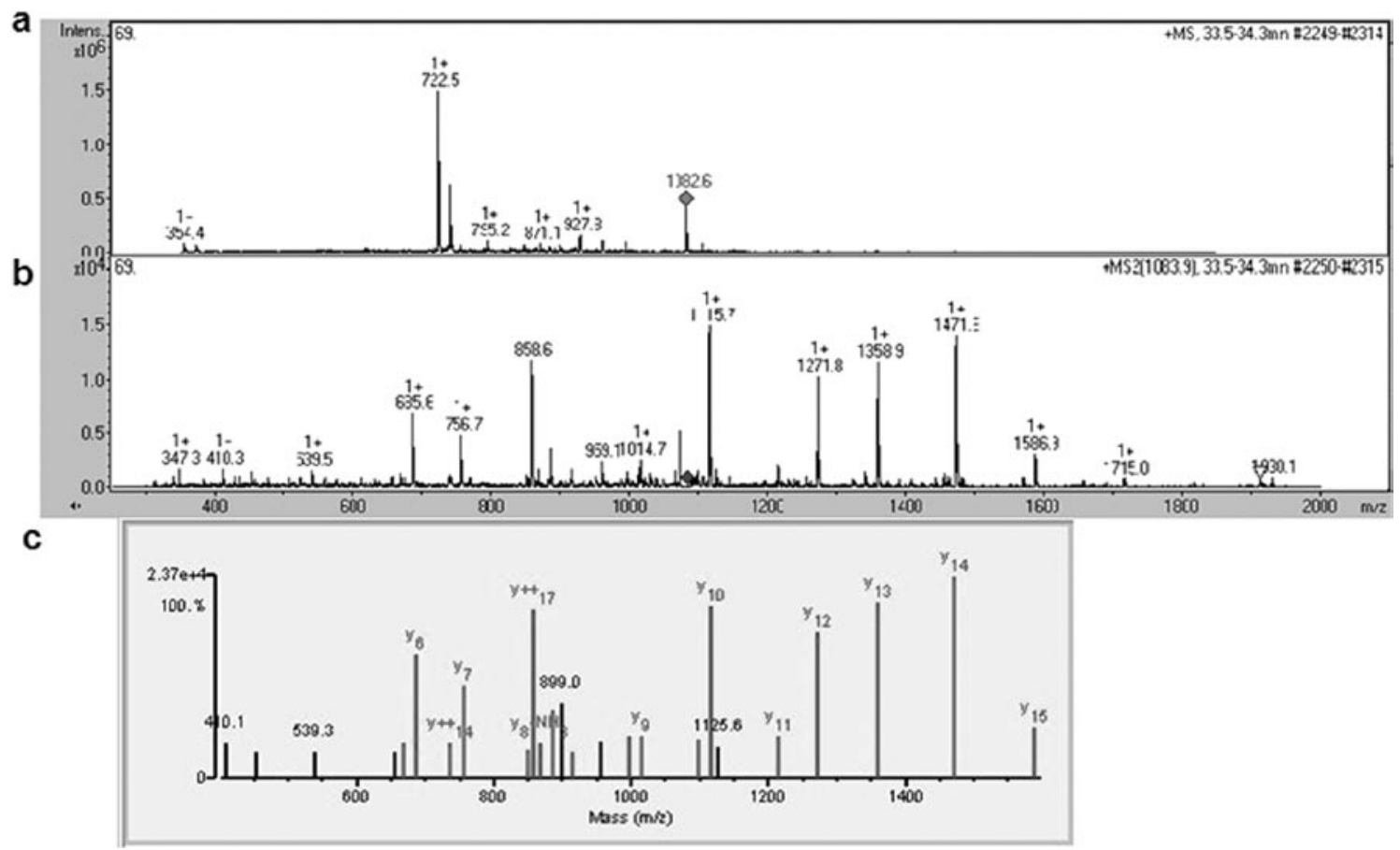

Figure 2. MS and MS/MS spectra of trypsin-digested spot 1. (a) LC-MS spectra of trypsin-digested of spot 1; $\alpha$-1-antitrypsin; precursor ion m/z is 1082.6 . ( $b$ and c) LC-MS/MS spectrum of a precursor ion with m/z 1082.6 marked by a lozenge in (a). The MS/MS spectrum is identified as the partial tryptic peptide VFSNGADLSGVTEEAPLKLSK from $\alpha$-1-antitrypsin processed with a Spectrum Mill workbench.

In-gel digestion. The gel pieces were rinsed 3 times in $60 \%$ methanol, $0.05 \mathrm{M}$ ammonium bicarbonate, and $0.005 \mathrm{M}$ DTT for $15 \mathrm{~min}$. The sample in the gel piece was reduced twice in $50 \%$ methanol, $0.05 \mathrm{M}$ ammonium bicarbonate, and $0.005 \mathrm{M}$ DTT for $10 \mathrm{~min}$. The gel pieces were dehydrated twice in $100 \% \mathrm{ACN}$ for $30 \mathrm{~min}$. Enzyme digestion was performed with an in-gel digestion reagent containing $10 \mu \mathrm{g} /$ $\mathrm{ml}$ sequencing-grade-modified trypsin (Promega, Madison, WI, USA) in $30 \% \mathrm{ACN}, 0.05 \mathrm{M}$ ammonium bicarbonate, and $0.005 \mathrm{M}$ DTT at $30^{\circ} \mathrm{C}$ for $16 \mathrm{~h}$. The samples were lyophilized over night with the use of Labconco Lyph-lock 1L Model 77400 (Labconco, Kansas, MO, USA) (16). Lyophilized samples were dissolved in $0.1 \%$ formic acid after $30 \mathrm{sec}$ were centrifuged at $21500 \mathrm{x}$ g for $5 \mathrm{~min}$ and the supernatant was stored at $-80^{\circ} \mathrm{C}$ as samples for MS until use.

LC-MS/MS analysis. LC-MS/MS was performed by using Agilent 1100 LC-MSD Trap XCT (Agilent Technologies, Palo Alto, CA, USA). Each sample (15 $\mu \mathrm{l})$ was applied and separated on a column (Zorbax 300SB-C18, $75 \mu \mathrm{m}$, $150 \mathrm{~mm}$, Agilent Technologies). The Agilent 1100 capillary pump was operated under the following conditions: Solvent A, $0.1 \%$ formic acid; Solvent B, ACN in $0.1 \%$ formic acid. Column flow, $0.3 \mu \mathrm{l} / \mathrm{min}$; primary flow $300 \mu \mathrm{l} / \mathrm{min}$. Gradient, $0-5 \min 2 \%$ B, $60 \mathrm{~min} 60 \%$ B. Stop time: $60 \mathrm{~min}$. Protein identification was performed in the Agilent Spectrum Mill MS proteomics workbench against the Swiss-Prot protein database search engine (http://kr.expasy.org/sprot/) and the MASCOT MS/MS Ions Search engine (http//www. matrixscience.com/search_form_select.html). The criteria for positive identification of proteins were set as follows: filter by protein score $>10.0$, and filter peptide by score $>8$, percentage scored peak intensity. The Spectrum Mill workbench can search MS/MS spectra using an MS/MS ion search $(17,18)$.

Western blotting. Total protein was used for electrophoresis with SDS-PAGE gels and transfer onto PVDF membranes at $90 \mathrm{~mA}$ for $78 \mathrm{~min}$. Protein $(1 \mu \mathrm{g})$ was used for each $2-\mathrm{DE}$. After that, the membranes were blocked over night at $4^{\circ} \mathrm{C}$ with TBS containing 5\% milk. Membranes were incubated with the primary antibody against $\alpha$-1-antitrypsin (polyclonal rabbit anti-human $\alpha$-1-antitrypsin, DakoCytomation, Glostrup, Denmark. 1:500) for $1 \mathrm{~h}$ at room temperature. Membranes were washed three times with TBS containing Tween-20 and once with TBS, and then incubated with the HRP-conjugated secondary antibody $(1: 10,000)$ for $1 \mathrm{~h}$ at room temperature. After washing, membranes were treated with a chemiflourescence reagent (ECL Plus Western Blotting Detection Reagents, GE Healthcare) and detected by using the ProXpress 2D Proteomic Imaging System (19).

\section{Results}

Differential spots between pancreatic cancer sera and healthy sera. After protein spots on the 2-DE gels were visualized by fluorescence staining, differences in the spot intensities between sera from patients with pancreatic cancer and healthy volunteers were analyzed with Progenesis Samespots software. At least 230 protein spots were matched on each 2-DE gel. Two spots were up-regulated in cancerous serum samples by $>1.5$-fold higher intensity (Fig. 1).

MS/MS analysis. The LC-MS/MS system identified the two up-regulated protein spots as $\alpha$-1-antitrypsin isoform 1 and 2. MS and MS/MS spectra of trypsin-digested spot 1 


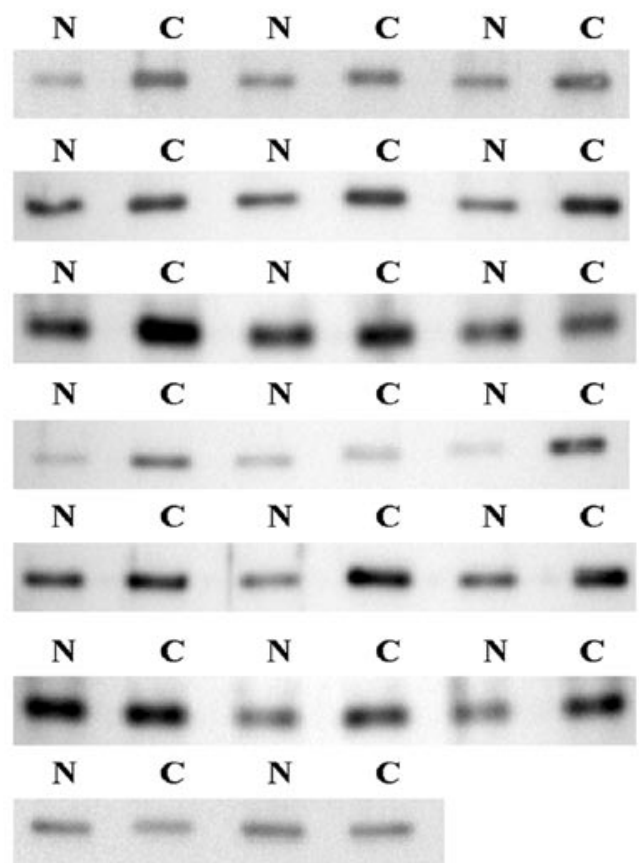

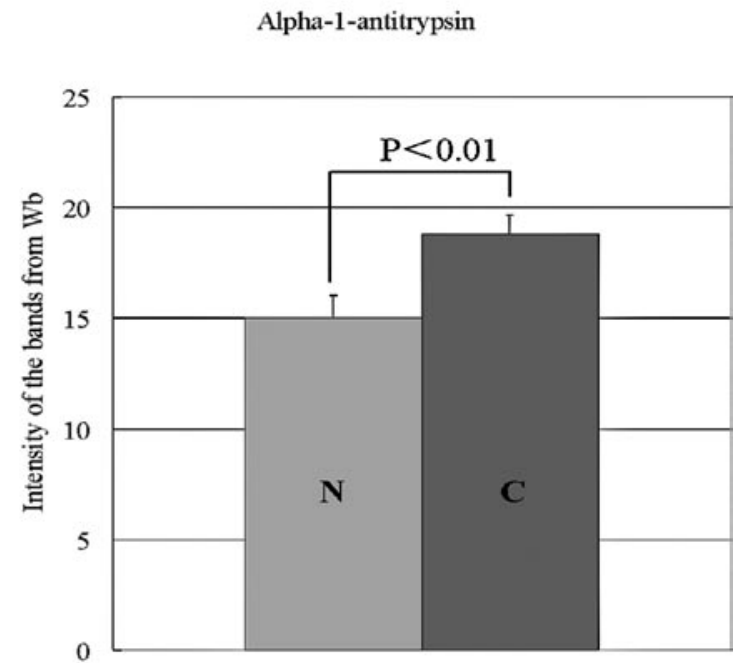

Figure 3. Western blot analysis of $\alpha$-1-antitrypsin (AAT) in pancreatic cancerous serum. (A) Sera from 20 patients with pancreatic cancer (C) and 20 normal donors $(\mathrm{N})$ were used for anti-AAT antibody. The expression of AAT was increased in pancreatic cancerous serum (70\%). (B) Comparison of the intensity of Western blot bands between cancerous serum and normal serum by Student's t-test $(\mathrm{n}=20, \mathrm{P}<0.01)$. The relative standard errors of cancerous serum samples and normal serum samples were 0.860 and 1.037 , respectively.

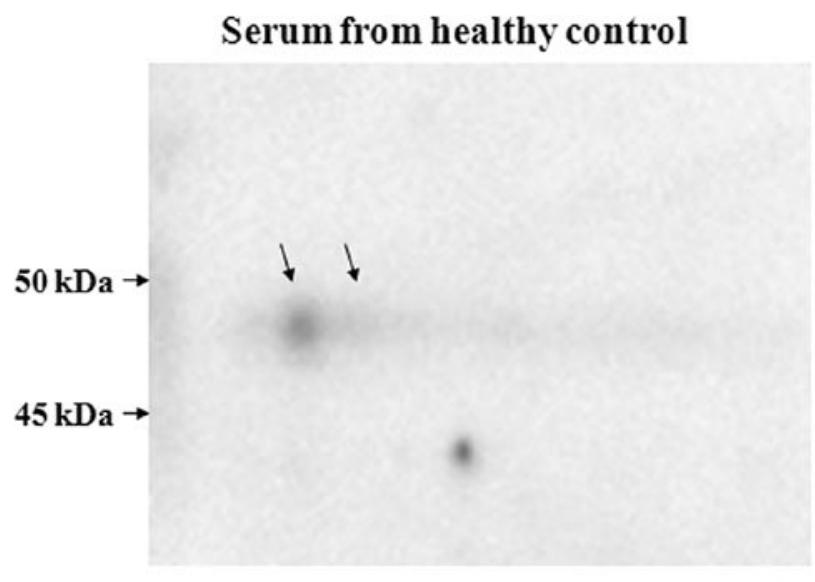

5.0

pH

5.5
5.0

Serum from patients with PC

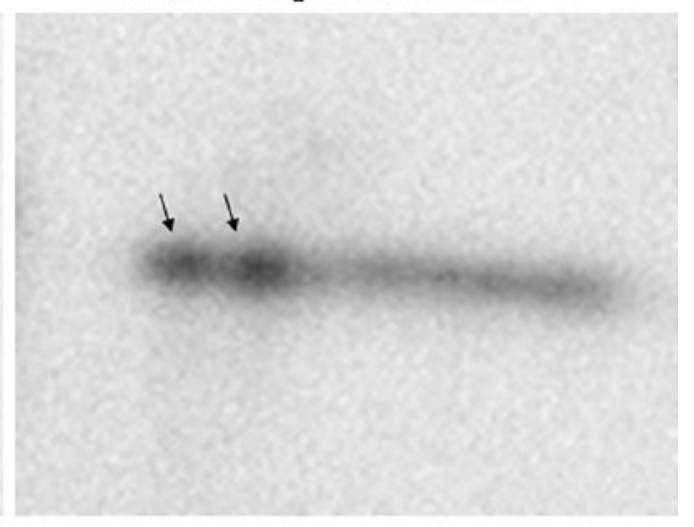

$\mathrm{pH}$
5.5

Figure 4. 2-D immunoblot analysis of $\alpha$-1-antitrypsin (AAT) in pancreatic cancerous serum. We performed 2-D immunoblotting with a pair of samples on pH 5.0-8.0 linear and confirmed the location sites of AAT isoforms on immunoblot membranes. Compared with non-cancerous serum, the up-regulated spots of AAT in cancerous serum were observed in the $\mathrm{pH}$ 5.0-5.5, 45-50 kDa area.

are shown in Fig. 2 and MS/MS data for the two isoforms are summarized in Table I.

Western blot analysis of $\alpha$-1-antitrypsin (AAT). As seen in Fig. 3A, compared with sera from healthy volunteers, up-regulated ATT in sera from PC patients was detected by Western blot analysis, and the average intensity of bands of $\alpha$-1-antitrypsin is shown in Fig. 3B. Location of ATT isoforms on the 2-DE gel was displayed by 2-D Western blot analysis (Fig. 4).

\section{Discussion}

In this study, we detected two up-regulated protein spots in sera from patients with PC compared with healthy volunteers. The two protein spots were identified as $\alpha$-1-antitrypsin (AAT) by LC-MS/MS. AAT belongs to acute phase protein (APP) whose expression is significantly increased in inflammation, trauma, infection and tumorigenesis. Many studies have suggested that serum levels of APP have a high clinical value in various cancer diseases including colorectal cancer 
(20), lung cancer (21), hepatoma (22), breast cancer (23) and others (24).

Protein level of serum AAT was significantly increased during inflammation trauma, infection, and tumorigenesis (20), especially in lung cancer (21) and liver cancer (25). AAT represents a diagnostic index of tumor diseases, highly sensitive but with low specificity (26). Up-regulation of AAT in some pathological conditions, such as malignant proliferation, is believed to be a part of protective physiological response (27). An increase of serum ATT levels is reported to be associated with acute malignancy and shorter survival (28). Therefore, AAT may be a valuable marker for prognosis in PC. Although circulating AAT is supplied primarily by hepatocytes and mononuclear phagocytes, AAT is also present in a variety of tissues and cells, including tumor cells $(29,30)$. More aggressive tumor growth associated with reduced local AAT expression (31). AAT with specific forms have multiple effects on tumor cell viability and promote tumorigenesis (30). Therefore, there is a possibility of production of AAT in pancreatic cancerous tissues. Presumably destruction of pancreatic cancerous tissues leads to abundant AAT release into the blood, resulting in increasing concentration in sera of PC patients.

Herein, we showed up-regulated AAT in sera of PC patients. However, since AAT is highly sensitive, it could be useful in early diagnosis of PC. Although it is difficult to diagnose the patients with PC in early stage, it is important to clarify if AAT is highly sensitive in early stage of PC. In order to confirm whether AAT is useful for developing new diagnostic or prognostic marker for PC, a large number of clinical investigations are needed in further study.

Tountas et al have reported AAT in PC patient sera (32). It is commonly believed that the specificity of ATT is low (33), but our data indicate that its serum isoforms might be more specific for diagnosis of PC. Electrophoretic techniques of 2-DE and Western blotting combined with LC-MS/MS in this study indicate AAT to be a candidate protein for biomarker in PC patient sera and also provide more visualized and detailed information for diagnosis or prognosis of PC. AAT can be separated into seven different isoforms in plasma with linear gradient $\mathrm{pH}$ 4.0-7.0 strips by 2-DE (34). Therefore, we will also depend on proteomics for clarifying the relationship between expression of those isoform levels of serum AAT and early $\mathrm{PC}$ in the future.

\section{References}

1. Jemal A, Siegel R, Ward E, Hao Y, Xu J and Thun MJ: Cancer statistics, 2009. CA Cancer J Clin 59: 225-249, 2009.

2. Goggins M, Canto M and Hruban R: Can we screen high-risk individuals to detect early pancreatic carcinoma? J Surg Oncol 74: 243-248, 2000.

3. Wasinger VC, Cordwell SJ, Cerpa-Poljak A, Yan JX, Gooley AA, Wilkins MR, Duncan MW, Harris R, Williams KL and Humphery-Smith I: Progress with gene-product mapping of the Mollicutes: Mycoplasma genitalium. Electrophoresis 16: 1090-1094, 1995.

4. Kuramitsu Y and Nakamura K: Proteomic analysis of cancer tissues: shedding light on carcinogenesis and possible biomarkers. Proteomics 6: 5650-5661, 2006.

5. Kuramitsu Y and Nakamura K: Current progress in proteomic study of hepatitis $\mathrm{C}$ virus-related human hepatocellular carcinoma. Expert Rev Proteomics 2: 589-601, 2005.
6. Ma YL, Peng JY, Zhang P, Huang L, Liu WJ, Shen TY, Chen HQ, Zhou YK, Zhang M, Chu ZX and Qin HL: Heterogeneous nuclear ribonucleoprotein $\mathrm{A} 1$ is identified as a potential biomarker for colorectal cancer based on differential proteomics technology. J Proteome Res 8: 4525-4535, 2009.

7. Petricoin EF, Ardekani AM, Hitt BA, Levine PJ, Fusaro VA, Steinberg SM, Mills GB, Simone C, Fishman DA, Kohn EC and Liotta LA: Use of proteomic patterns in serum to identify ovarian cancer. Lancet 359: 572-577, 2002.

8. Li J, Zhang Z, Rosenzweig J, Wang YY and Chan DW: Proteomics and bioinformatics approaches for identification of serum biomarkers to detect breast cancer. Clin Chem 48: 1296-1304, 2002.

9. Bañez LL, Prasanna P, Sun L, Ali A, Zou Z, Adam BL, McLeod DG, Moul JW and Srivastava S: Diagnostic potential of serum proteomic patterns in prostate cancer. J Urol 170: 442-446, 2003.

10. Adam BL, Qu Y, Davis JW, Ward MD, Clements MA, Cazares LH, Semmes OJ, Schellhammer PF, Yasui Y, Feng Z and Wright GL Jr: Serum protein fingerprinting coupled with a pattern-matching algorithm distinguishes prostate cancer from benign prostate hyperplasia and healthy men. Cancer Res 62: 3609-3614, 2002.

11. Vlahou A, Schellhammer PF, Mendrinos S, Patel K, Kondylis FI, Gong L, Nasim S and Wright GL Jr: Development of a novel proteomic approach for the detection of transitional cell carcinoma of the bladder in urine. Am J Pathol 158: 1491-1502, 2001.

12. Bloomston M, Zhou JX, Rosemurgy AS, Frankel W, MuroCacho CA and Yeatman TJ: Fibrinogen gamma overexpression in pancreatic cancer identified by large-scale proteomic analysis of serum samples. Cancer Res 66: 2592-2599, 2006.

13. Yu KH, Rustgi AK and Blair IA: Characterization of proteins in human pancreatic cancer serum using differential gel electrophoresis and tandem mass spectrometry. J Proteome Res 4: 1742-1751, 2005.

14. Sun ZL, Zhu Y, Wang FQ, Chen R, Peng T, Fan ZN, Xu ZK and Miao Y: Serum proteomic-based analysis of pancreatic carcinoma for the identification of potential cancer biomarkers. Biochim Biophys Acta 1774: 764-771, 2007.

15. Tanaka T, Kuramitsu Y, Fujimoto M, Naito S, Oka M and Nakamura K: Downregulation of two isoforms of ubiquitin carboxyl-terminal hydrolase isozyme L1 correlates with high metastatic potentials of human SN12C renal cell carcinoma cell clones. Electrophoresis 29: 2651-2659, 2008.

16. Kuramitsu Y, Miyamoto H, Tanaka T, Zhang X, Fujimoto M, Ueda K, Tanaka T, Hamano K and Nakamura K: Proteomic differential display analysis identified upregulated astrocytic phosphoprotein PEA-15 in human malignant pleural mesothelioma cell lines. Proteomics 9: 5078-5089, 2009.

17. Takashima M, Kuramitsu Y, Yokoyama Y, Iizuka N, Harada T, Fujimoto M, Sakaida I, Okita K, Oka M and Nakamura K: Proteomic analysis of autoantibodies in patients with hepatocellular carcinoma. Proteomics 6: 3894-3900, 2006.

18. Takashima M, Kuramitsu Y, Yokoyama Y, Iizuka N, Fujimoto M, Nishisaka T, Okita K, Oka M and Nakamura K: Overexpression of alpha enolase in hepatitis $\mathrm{C}$ virus-related hepatocellular carcinoma: association with tumor progression as determined by proteomic analysis. Proteomics 5: 1686-1692, 2005.

19. Kuramitsu Y, Harada T, Takashima M, Yokoyama Y, Hidaka I, Iizuka N, Toda T, Fujimoto M, Zhang X, Sakaida I, Okita K, Oka $M$ and Nakamura K: Increased expression and phosphorylation of liver glutamine synthetase in well-differentiated hepatocellular carcinoma tissues from patients infected with hepatitis C virus. Electrophoresis 27: 1651-1658, 2006.

20. Stamatiadis AP, St Toumanidou M, Vyssoulis GP, Manouras AJ and Apostolidis NS: Value of serum acute-phase reactant proteins and carcinoembryonic antigen in the preoperative staging of colorectal cancer. A multivariate analysis. Cancer 65: 2055-2057, 1990.

21. Kasprzyk M, Dyszkiewicz W, Zwaruń D, Leśniewska K and Wiktorowicz K: The assessment of acute phase proteins as prognostic factors in patients surgically treated for non-small cell lung cancer. Pneumonol Alergol Pol 76: 321-326, 2008.

22. Kang X, Sun L, Guo K, Shu H, Yao J, Qin X and Liu Y: Serum protein biomarkers screening in HCC patients with liver cirrhosis by ICAT-LC-MS/MS. J Cancer Res Clin Oncol 136: 1151-1159, 2010.

23. Thompson DK, Haddow JE, Smith DE and Ritchie RF: Elevated serum acute phase protein levels as predictors of disseminated breast cancer. Cancer 51: 2100-2104, 1983. 
24. Juan HF, Chen JH, Hsu WT, Huang SC, Chen ST, Yi-Chung Lin J, Chang YW, Chiang CY, Wen LL, Chan DC, Liu YC and Chen YJ: Identification of tumor-associated plasma biomarkers using proteomic techniques: from mouse to human. Proteomics 4: 2766-2775, 2004.

25. Hong WS and Hong SI: Clinical usefulness of alpha-1-antitrypsin in the diagnosis of hepatocellular carcinoma. J Korean Med Sci 6: 206-213, 1991.

26. Schena M, Quadri A, Ragazzoni G and Corti P: Alpha 1-antitrypsin as a tumor marker. Quad Sclavo Diagn 21: 87-96, 1985.

27. Marchandise FX, Mathieu B, Francis C and Sibille Y: Loca increase of antiprotease and neutrophil elastase-alpha 1-proteinase inhibitor complexes in lung cancer. Eur Respir J 2: 623-629, 1989.

28. Tahara E, Ito H, Taniyama K, Yokozaki H and Hata J: Alpha 1-antitrypsin, alpha 1-antichymotrypsin, and alpha 2-macroglobulin in human gastric carcinomas. a retrospective immunohistochemical study. Hum Pathol 15: 957-964, 1984

29. Carlson JA, Rogers BB, Sifers RN, Hawkins HK, Finegold MJ and Woo SL: Multiple tissues express alpha 1-antitrypsin in transgenic mice and man. J Clin Invest 82: 26-36, 1988.
30. Zelvyte I, Sjögren HO and Janciauskiene S: Effects of native and cleaved forms of alpha1-antitrypsin on ME 1477 tumor cell functional activity. Cancer Detect Prev 26: 256-265, 2002.

31. Huang H, Campbell SC, Nelius T, Bedford DF, Veliceasa D, Bouck NP and Volpert OV: Alpha1-antitrypsin inhibits angiogenesis and tumor growth. Int J Cancer 112: 1042-1048, 2004.

32. Tountas Y, Sparos L, Theodoropoulos C and Trichopoulos D: Alpha 1-antitrypsin and cancer of the pancreas. Digestion 31: 37-40, 1985.

33. Irigoyen Oyarzabal AM, Amiguet García JA, López Vivanco G Genollá Subirats J,Muñoz Villafranca MC,Ojembarrena MartínezE and Liso Irurzun P: Tumoral markers and acute-phase reactants in the diagnosis of pancreatic cancer. Gastroenterol Hepatol 26: 624-629, 2003.

34. Mateos-Cáceres PJ, García-Méndez A, López Farré A, Macaya C, Núñez A, Gómez J, Alonso-Orgaz S, Carrasco C, Burgos ME, de Andrés R, Granizo JJ, Farré J and Rico LA: Proteomic analysis of plasma from patients during an acute coronary syndrome. J Am Coll Cardiol 44: 1578-1583, 2004. 